\title{
A PRODUÇÃo dA ESCALA METROPOLITANA E DO SEU PESQUISADOR: ELEMENTOS DE RITMANÁLISE
}

\author{
Flávia Elaine da Silva Martins*
}

\section{RESUMO:}

Este artigo busca compreender a produção do espaço metropolitano a partir da ampliação das relações de crédito e de endividamento na composição dos negócios imobiliários urbanos. São enfocados neste contexto a abertura de capital nas incorporadoras imobiliárias e a presença dos leilões de imóveis como agentes imobiliários. A produção em escala dos imóveis a serem comercializados pelas incorporadoras e a abrangência da escala metropolitana como localização destes lançamentos colocam a produção social da escala urbana como aspecto a ser pesquisado na geografia, a partir do pesquisador que inclui seu cotidiano como fonte de pesquisa.

PALAVRAS - CHAVE: metropolitano, crédito, endividamento, escala, cotidiano.

\section{ABSTRACT:}

This article seeks to understand the production of the metropolitan area from the extension of credit agreements and debt in the composition of urban real estate. Are approaches in this context the opening of capital in real estate development and the presence of auction properties and real estate agents. The production scale of the property being marketed by developers and scope of the metropolitan scale and location of these launches put the social production of urban scale as feature to search for in geography from the researcher that includes your daily source of research.

KEY WORDS: metropolitan, credit, debt, scale, everyday life.

\section{Introdução}

Este artigo procura abordar algumas transformações pelas quais o modo de vida urbano vem passando nas metrópoles, por meio do estudo dos conteúdos destas e a partir da transformação do próprio pesquisador, neste caso, geógrafos implicados nas pesquisas dos espaços em que vivem. O positivo distanciamento entre sujeito e objeto não é mais possível nas nossas pesquisas, e quando isso se dá em uma pesquisa atual, ocorre à custa de um conhecimento que perde sua força. Ao mesmo tempo, quando os pesquisadores decidem se aprofundar, por exemplo, no estudo dos negócios urbanos, encontram barreiras gigantes. Negócios são feitos a portas fechadas, como a nossa experiência vem nos mostrando.
O cotidiano passa assim a se apresentar ao pesquisador como a sua maior fonte de informação.

A insistência em elucidar as estreitas ligações de um pesquisador com o seu "objeto" de pesquisa, sem confundi-los, reside no fato de que a vida cotidiana é um plano de pesquisa que nos une de forma totalizante, nos limites e na potência que isso pode significar. A ambiguidade da percepção e do vivido, entretanto, não torna esse caminho de desvendamento muito tranquilo.

Temos como proposta neste artigo apresentar uma relação sujeito-objeto da pesquisa que parta do estudo do cotidiano e exige o cotidiano do próprio pesquisador como fonte de pesquisa e análise crítica, seguindo para a 
proposição de uma sociedade urbana como portadora de uma prática espacial que pode conter respostas desviantes das práticas sociais e espaciais cotidianas.

*

Tentaremos um caminho pela ritmanálise. O que nos provoca a seguir por esse caminho é o já apresentado questionamento do distanciamento entre pesquisado e pesquisador e mais do que isso, é a impossibilidade de separação dos ritmos que envolvem ambos na nossa sociedade urbana atual. Os elementos da ritmanálise irão compor esta pesquisa, ou melhor, já estão nela desde a sua conformação.

De forma central ao texto apresento um trecho que Henri Lefebvre nos traz em seu livro Elementos de Ritmanálise, Introdução aos conhecimentos dos ritmos. "O ritmanalista (...) não terá estas obrigações metodológicas: se torna passivo, esquece o seu saber para o reapresentar por inteiro na interpretação. Ele escuta, antes o seu corpo. Ele apreende os seus ritmos, para em seguida apreciar os ritmos externos. Seu corpo lhe serve de metronome". (LEFEBVRE, 1992, p. 39)

A proposta deste artigo é apresentar alguns dos elementos de ritmanálise utilizados na pesquisa de doutorado que dá origem a este artigo, todos eles destacados a partir do cotidiano da pesquisadora que aqui escreve. É necessário lembrar que esta pesquisa também é fruto de debates de um grupo $^{1}$, que deram origem ao movimento feito a seguir, de tensão entre o ritmanalista e o analista (institucional).

Para isso, retornando brevemente ao livro citado acima, podemos captar um bom diálogo entre a análise institucional e a ritmanálise presente no prefácio de René Lourau para Elementos de Ritmanálise. Lourau aponta que a reabilitação do sensível, para Lefebvre, é a reabilitação da sensibilidade do observador, do pesquisador, em ocorrência da ritmanálise. O ritmanalista toma por referência os seus próprios ritmos. Ele trabalha com seu corpo que trabalha. René nos lembra ainda que a ritmanálise deve seguir do abstrato ao concreto.
O "diálogo" entre autores pode nos sugerir um debate e vamos dar início a ele por meio da constituição do sujeito e do objeto. Ambos autores lidam estrategicamente com noção de sujeito, e portanto, de forma consciente, com a separação e a união oportunas entre sujeito e objeto, assim como com a inversão de papéis. O analista se envolve com a análise, dela faz parte, atua e se institui. O ritmanalista se abandona por algum momento, estuda o contato entre os seus ritmos e os ritmos alheios aos seus, discernindo-os, entretanto. O analista tem mais forte a consciência de sua atuação para transformação de determinada relação, para a sua instituição, o ritmanalista usaria de sua sensibilidade para apreender a transformação de um ritmo alheio que pode estar a se tornar muito íntimo, nele próprio.

Agora vamos discutir sobre as escalas urbanas e o cotidiano, então sobre as mediações. Podemos compreender que o urbano se apresenta como uma massa disforme de instituições, indistintas muitas vezes. Esta escala urbana, produzida a partir da indeterminação das instituições, seria melhor apreendida pelos ritmos. Entretanto, assim como as escalas se interpenetram, podemos observar melhor e ver que essa massa disforme, o cotidiano urbano, é repleta de instituições sem limites conhecidos às quais cada pessoa se apresenta destituída ou a se instituir. Instituir-se em uma escala, pode significar destituição em uma escala imediatamente inferior ou superior.

"Es raro que um individuo, por aislado que parezca, no sea menbro de um retículo o um filamento, a menudo sin saberlo. La mayor parte de la gente participa em vários de este grupo "informales". Detengamos aqui este breve inventario de la cotidianidad. Para compreenderla, hemos recurrido a uma noción celebre y obscura, de alienacion. Toda actividad viva e consciente que se pierde, se extravia, se deja arrancar de si mesma, y por conseguinte se aparta de su plenitud, está alienada. El estudo de la vida cotidiana obriga los filósofos a flexibilizar e concretizar esta noción. Alienación y desalienación se 
entremezclan, lejos de excluirse. Lo que libera e "desaliena"en relación a una actividad ya alienada puede resultar alienante, $y$, em consequência, exigir otras desalienações. Y así sucesivamente, en um movimiento dialéctico, es decir, hecho de contradiciones siempre resueltas y siempre renascientes." (LEFEBVRE, 1978, p. 85).

O movimento apresentado acima é o substrato da prática cotidiana. A prática espacial nos remete a um cotidiano constituído a partir de fragmentos. Para uma possível noção de totalidade, para essa, a ritmanálise poderia nos dar pistas. Esta é a tensão de um conceito no outro.

\section{Elementos de ritmanálise}

Anuncio o contexto geral da pesquisa da qual este enfoque faz parte, que é o ritmo de produção do espaço em escala, imposto ao urbano por meio das incorporadoras de capital aberto e sobre a presença das dívidas no modo de vida urbano. A partir do corpo geral das pesquisas, anuncio algumas constatações: a pressão sobre os terrenos urbanos, na formação dos bancos de terras, aumentou os seus preços; os bancos de terras são formados em terras periféricas disponíveis, provocando a formação de novos centros, implicando em "expulsões" e intensificando as grandes distâncias urbanas. Esta pressão se dá de forma simultânea em muitas metrópoles brasileiras, apresentando o processo de forma generalizada às diferentes realidades urbanas; a dívida de longo prazo se torna, cada vez mais, um dos únicos acessos possíveis à moradia, cada vez mais encarecida e difundida nos diversos segmentos de renda; o pagamento destas dívidas está internamente conectado à remuneração do capital financeiro internacional e o não pagamento apresentará um agenciamento espacial e cotidiano - mudanças, expulsões - a ser realizado pelos endividados.

\section{Abertura de Capitais nas incorporadoras}

$\mathrm{O}$ ano de 2006 pode ser considerado um marco no processo de abertura de capitais pelas incorporadoras brasileiras, nas chamadas IPO's, initial public offering, quase como em decorrência de um processo longo de mundialização dos capitais - que envolveu a desregulamentação das praças financeiras e internacionalização dos capitais - e uma ampla política de crédito apoiada e favorecida pelo Estado.

As empresas que abriram seus capitais adotaram novas agendas, novos ritmos de lançamentos, se reestruturaram internamente, assim como se reestruturou o seu raio de atuação, passando a englobar as regiões metropolitanas de todo o país. Este conjunto de alterações visou a programar a remuneração esperada e adequada ao capital que passou a fazer parte das incorporadoras com as chamadas IPO's. Um fato importante diante deste quadro de expansão foi a criação dos bancos de terras pelas incorporadoras em muitas áreas urbanas do país, elevando os preços da terra e implicando uma escala de produção urbana necessária para assegurar os rendimentos e ritmos financeiros.

Este é um caminho para abordar o meio pelo qual os ritmos financeiros mundiais são apresentados, nível por nível, redefinindo o modo de vida metropolitano, e o estudo da abertura de capitais, a comercialização dos lançamentos imobiliários e as dívidas geradas a partir daí, cria a oportunidade de investigar o longo prazo nos processos de endividamento urbano. Ritmo fictício a redefinir outros ritmos. Passamos a lidar, dessa forma, não só com a produção do espaço, mas com a produção do espaço nas determinações do capital que ingressa financeiramente nas incorporadoras, provocando a produção da escala e do ritmo inerente a ela. Não se trata de uma escala de atuação dada, mas uma escala a ser produzida e socialmente reproduzida.

A abertura de capitais nas incorporadoras responde a uma política de incremento do crédito, fazendo com que cresçam os pedidos de financiamentos para a compra dos "produtos" fabricados pelas incorporadoras, casas, apartamentos e lotes, apoiados em uma política acordada entre o Estado e as instituições bancárias, de oferecimento de crédito aos consumidores. Às dívidas de médio e curto prazos, 
atualmente tão difundidas na administração das contas domésticas, inclusive das famílias mais pobres, se somam os financiamentos de longo prazo para a moradia. Esta política de crédito visa atender todas as faixas de rendimento, e podemos encontrar desde os fundos para habitação popular até a elevação do montante a ser financiado, atingindo imóveis da classe média. Visivelmente, o leque se abre e o objetivo é a ampliação do crédito em todos os níveis de renda.

As recentes conexões entre o financeiro e o imobiliário - e a produção do urbano - se desdobram em inúmeras formas e denominações. A geografia vem realizando uma série de estudos que buscam compreender o processo pelo qual o urbano foi absorvido pela lógica do dinheiro, tornada lógica do capital, e este momento de financeirização do capital - capital que desde o início porta a lógica financeira, mas agora esta lógica assume forma predominante - provoca o necessário desvendamento de continuidades e rupturas da forma e conteúdo urbanos, de relações sociais urbanas a reproduzirem criticamente uma determinada escala financeira de produção. Os esforços têm se distribuído, por exemplo, na compreensão da abstração dos títulos de propriedade urbana e da sua mobilidade, da sua circulação financeira, dos fundos de investimento presentes no mercado imobiliário, dentre outros.

Este artigo se insere neste movimento maior e se aproveita dele, assim como espera colaborar com ele ao final. Tem foco específico na abertura de capitais que as incorporadoras promoveram entre os anos de 2006 e 2007 e buscará, em um nível mais profundo, sondar a conexão deste "evento" com outros estudos, apresentando um ponto de vista sobre a forma da inserção da produção do urbano em que vivemos em uma escala financeira de abrangência mundial, e a contradição desta produção, deste espaço produzido em escala dinâmica e préimplicada.

É necessário fazer uma ressalva de que a abertura de capitais, de uma forma geral, para empresas de diversos setores, é uma forma de captação de recursos presente na bolsa de valores já há algumas décadas, e que conheceu outros momentos de ápice, como no ano de 1998, por exemplo. O que se pretende aqui é estudar esta forma de captação de recursos a partir do sistema financeiro, com implicações diretas sobre a escala de produção do espaço urbano, e um novo "pico" de crescimento de empresas abrindo o seu capital, nos anos de 2006, 2007, fortemente marcado pela presença das incorporadoras. A abertura de capitais está presente nos diversos setores, assim, a análise dos ritmos apresentados aqui para a construção civil guarda paralelos com o mesmo processo nestes outros setores, como por exemplo o "setor da educação privada", com a forte presença de capitais internacionais, assim como constatamos na construção civil. A produção desta escala, de remuneração, envolve a sociedade de maneira totalizante.

Este olhar para as Ipo's na construção civil acabou por ter delimitações bem definidas. Temos os anos de 2006 e 2007 como o momento de corrida das incorporadoras à bolsa, amplamente divulgado e já com alguma repercussão nos estudos econômicos. Segundo TAVARES, "houve um importante movimento de acesso (das incorporadoras) ao mercado de ações como forma de captação de recursos, a partir do segundo semestre de 2005. (...)" (TAVARES, 2008, p. 47).

Da mesma maneira, podemos tomar a crise norte-americana de financiamento dos Subprime, no último trimestre de 2008, como um ponto crítico de estudo desta forma, por anunciar, em um mercado e uma sociedade diferente dos nossos, os termos potencialmente críticos dos financiamentos apresentados aqui. Como estudamos as relações de crédito, em longo prazo, não podemos acomodar o tempo da pesquisa num tempo linear e sucessivo de crédito e dívida. Será um recurso de análise desta pesquisa que associemos, em um mesmo tempo, dívidas e créditos de períodos e locais diferentes.

O foco fecha ainda na abertura de capitais, em especial para o setor da construção civil e para as incorporadoras. Existem diferenças entre a abertura de capitais promovida pelas incorporadoras e a abertura de capitais em outros 
setores. As incorporadoras necessitam de prazos mais longos para a realização dos ciclos de produção e consumo que participam do conjunto de sua produção, possuem diferenças na rotação do capital dentro da produção e na composição orgânica das empresas.

Segundo TAVARES, "de uma forma geral, existe uma característica especial da construção civil, a presença do longo prazo, de uma linha de produção atípica e com muitas variáveis e do tamanho relativamente pequeno ${ }^{2}$ destas empresas. (TAVARES, 2008, p. 79)".

A abertura de capitais pelas incorporadoras teria sido uma resposta à ampliação de crédito feita em níveis abrangentes pelo mercado e pelo Estado, como já vimos acima. Em uma situação de crescimento, baseada nas linhas de crédito, a oportunidade de acompanhar o crescimento foi a abertura de capitais, e não o crescimento por endividamento. A captação de recursos com a abertura de capitais serviria para a compra de terrenos, a formação de Land Banks, e para as aplicações financeiras. (TAVARES, R. 2008).

Ainda segundo a autora, alguns marcos jurídicos e elementos de conjuntura econômica, como um maior aporte de recursos para os sistemas nacionais de financiamentos, favoreceram o aumento do volume de atividade das incorporadoras. Temos então que a abertura de capitais das incorporadoras se encontra em um conjunto maior de transformações e ações, possuindo características especiais.

Sabemos que "onze empresas emitiram ações no período de 2005 a março de 2007 Brascan, Company, Camargo Corrêa, Cyrella, Even, Gafisa, Klabin Segall, PDG Realty, Rodobens, Rossi e Tecnisa, $(. . .)^{\prime \prime 3}$, o que nos define uma amostra exploratória para acompanhar, por meio dos seus lançamentos, da evolução nas bolsas, dentre outras coisas.

Com a crise americana dos subprime, rapidamente tornada uma crise mundial, temos um quadro de retração completa da abertura de capitais, definindo o "fim" temporário do período demarcado aqui. Uma empresa de capital aberto pode fechar seu capital novamente, realizando uma oferta de recompra das ações que estão em circulação. Deve informar, no caso brasileiro, a CVM - comissão de valores mobiliários-, e em seguida cancelar sua listagem na bolsa de valores. Essa manobra pode ser utilizada de forma fraudulenta por empresas.

\section{Securitização}

Diante da crise, as incorporadoras readequaram o seu ritmo de lançamentos e mudaram as negociações futuras na aquisição dos terrenos, realizando-as por meio de permutas e não de aquisição em dinheiro, mas o processo que importa nesta pesquisa tem continuidade, pois, em parte, a abertura de capitais provocou uma alteração profunda nas escala de produção das unidades habitacionais, comercias e no seu financiamento, e as incorporadoras que não puderem responder às demandas do capital novo serão incorporadas por outras, e em um nível maior, serão incorporadas pelos bancos. Da mesma forma, a securitização das dívidas dos compradores se torna um elemento de "captação de recursos" pelas incorporadoras, que transferem estas das dívidas para as instituições bancárias. Ou por meio da reestruturação das incorporadoras e construtoras, ou pela transferência das dívidas, a escala mundial financeira se apresenta sobre a produção do urbano, e os tópicos abaixo procurarão de forma resumida trazer alguns elementos que contribuem para o desvendamento de uma escala necessária de produção urbana a ser reproduzida socialmente.

A securitização é vista como uma forma de receita para as incorporadoras, realizada com base na dívida dos compradores dos lotes, casas, apartamentos, em toda a forma de endividamento. Estas dívidas são "vendidas" para financiadores maiores, que passarão a administrálas. "O mecanismo da securitização amplia as possibilidades de captação de recursos e de acesso ao financiamento às incorporadoras e construtoras, por meio do acesso direto ao mercado de capitais, e reduz, teoricamente, os custos e riscos da captação de recursos 
financeiros, ou seja, de endividamento das próprias incorporadoras. Assim, "a securitização possibilitaria uma aceleração do tempo de giro do capital das empresas, através de transformação dos direitos a receber pela venda dos imóveis a prazo em títulos vendidos à vista (grifo meu). Dessa forma, a incorporadora não necessita esperar pelo vencimento da dívida dos mutuários para recuperar o capital investido". (BOTELHO, 2005, p. 96)

Esse movimento de transferência das dívidas implica uma penetração maior do ritmo de remuneração financeira mundial nas relações locais de compra e venda dos imóveis, e também aumenta o risco da dívida. A dívida é vendida aos níveis financeiros superiores, criando uma estrutura hierárquica desde o endividado até instituições de grande porte. Esse encadeamento possui um preço, que aumenta conforme a análise do risco da dívida. Este preço está acomodado no centro da dívida.

Como o objetivo deste trabalho é abordar a produção social da escala, a partir da formação de bancos de terras, da elevação do preço dos imóveis e das dívidas vendidas aos bancos, assim como das execuções destas dívidas, buscaremos as necessárias conexões ao longo da pesquisa. Devemos entretanto incorporar, a partir daqui, que a transferência da dívida pelos níveis financeiros, implica, no sentido contrário, a programação cotidiana do trabalhador endividado, empregado ou não, no ritmo de pagamento destas dívidas, ritmos que obedecem aos definidos nas esferas do capital mundializado.

\section{Bancos de terras das incorporadoras}

O enorme aporte de capital feito nas incorporadoras, como vimos acima, provocou a necessidade de formação de um banco de terras (land banks) por cada uma das incorporadoras e uma disputa entre elas, gerando negociações em extensas áreas metropolitanas, assim como uma verdadeira corrida por terras em áreas urbanas de todo o país. Estas negociações foram feitas de diversas formas, inicialmente por compra, e quando a crise começou a dar seus sinais, as negociações passaram a ser por meio de permutas. A repercussão deste capital mundial disponível para a compra dos terrenos provocou a elevação dos preços das terras negociadas, e consequente elevação do preço de todo e qualquer metro quadrado negociado no urbano. O boom imobiliário pode ser traduzido em boom de preços do imobiliário e em um longo prazo, boom nos valores das dívidas e nos endividamentos.

O estudo da formação dos bancos de terras representa nesta pesquisa o atributo espacial pelo qual o atual estágio de financeirização mundial passa a compor o modo de vida urbano, e isso deverá ser compreendido nos diferentes níveis de organização administrativa das cidades. Entretanto, o conteúdo maior está em compreendermos o processo de valorização do capital (do valor) por meio do endividamento, por meio da assignação do trabalho futuro, que deve remunerar esta valorização, por meio da precificação, por exemplo, na figura da renda da terra, dos bancos de terras colocados neste circuito. A atualização necessária é a de que a exploração do trabalho que deverá pagar a financeirização do capital expressa nestes bancos de terras, mas este pagamento tem que ser programado em um longo prazo, na organização do modo de vida, além de que a formação dos bancos de terras é realizada com base na generalização de todo e qualquer urbano como um urbano portador da metrópole. O banco de terras é o elemento espacial que intensifica estas conexões.

\section{Outros elementos}

A penetração de grandes incorporadoras em cidades menores passa pela associação destas com as construtoras e incorporadoras locais. A lógica da formação dos bancos de terras inclui as cidades menores, transferindo com os lançamentos imobiliários as relações de crédito e endividamento aos compradores.

Além da associação dos incorporadores, a atuação do Estado no sentido de potencializar 
os negócios urbanos já está presente, por meio da elaboração atualizada dos planos diretores, nas formas possíveis de desdobrar a propriedade da terra, de negociar os potenciais de construção. A partir do que conhecemos em São Paulo, e a forma como o plano diretor de São Paulo apresentou formas diversas de negociação com a terra urbana - outorgas onerosas, transferências de potenciais de construção - já podemos identificar estes mesmos recursos nos planos diretores de municípios menores. Assim, atualmente, quando a incorporação chega a um município, já possui um conjunto de instrumentos para negociar a terra, instrumentos que foram gestados nos ambientes metropolitanos de intensa disputa pela terra urbana.

A escala metropolitana, desta forma, pode ser apresentada em cidades pequenas ou médias. Um modo de observar isso é a presença de formas abstratas de regulação e troca dos espaços, apresentados após o Estatuto da Cidade e presente nos planos diretores diversos espalhados pelo Brasil, ou mesmo do processo de periferização observados em cidades pequenas. Os municípios se tornaram metrópoles em potencial, na forma de negociar e produzir o espaço urbano, independentemente do seu tamanho. A realização desta metropolização no modo de vida urbano é o que se pode pesquisar. Aqui, o olhar está nas relações de crédito e dívida, mas certamente existem outras formas de entender a alteração destes ritmos.

\section{Generalização da dívida: uma abordagem dos leilões}

O estudo dos leilões tem o seu limite prédefinido. Estamos tratando de um processo de expulsão - como hipótese - em ritmos mais lentos do que aqueles apresentados, por exemplo, na demolição de uma favela, uma forma de expulsão abrupta e violenta, que já pudemos acompanhar em diversas pesquisas dentro da geografia urbana e agrária, da arquitetura e do urbanismo. Além disso, os leilões só nos apresentarão as pessoas que, em algum momento, estiveram em condições de se endividar. Esta ressalva é necessária e esta pesquisa só faz sentido se for pensada de forma associada às outras que optaram por compreender a violência das expulsões tradicionais e também cotidianas do urbano, e por aquelas que ousaram compreender o modo de vida dos que não se enquadram nem como pessoas endividáveis.

Ainda assim, um caminho pelos leilões nos traz a possibilidade de abordar a relação crítica presente no crédito, vista aqui na forma do endividamento. Tomemos por início a tomada de empréstimos para a casa própria e reprodução possível destes juros no modo de vida do trabalhador. Sharon Zukin nos apresenta algumas relações, expondo a compra de um imóvel em seus imbricamentos: "Comprar ou alugar uma casa é provavelmente o momento mais significativo do consumo, e certamente o gasto mais importante na vida das pessoas. Mas o comprador é cercado por um contraditório aspecto de autonomia e dependência ao mesmo tempo. Por um lado, comprar um teto e um pouco de terra ao redor significa libertação do senhorio ou senhoria, e da proximidade com a família. Por outro lado, o despejo se torna tão próximo quanto, nas mãos do banco ou do proprietário da hipoteca, pois o pagamento em intervalos regulares obriga ao emprego estável, poupança, e o mais importante, a permanecer no lugar. Comprar um imóvel também indica uma relação entre investimento e gasto. Nos últimos quarenta anos, comprar uma casa se tornou um bilhete de loteria na grande subida dos valores das terras, de maneira paralela à tradicional forma de assegurar abrigo. Ademais, comprar uma casa pode significar um custo elevado (...). A mobilidade social que isto implica, pode, em longo prazo, trazer apenas a acumulação da desvalorização de bens. No curto prazo, por outro lado, devido aos custos de comprar e manter uma casa, a compra implica a colocação do morador no mercado imobiliário e configura a sua entrada no mercado de trabalho" (ZUKIN, 1993, p.11) ${ }^{4}$

O que apreendemos é que o desencadeamento da dívida em longo prazo provoca uma subordinação do trabalhador - e da venda da única mercadoria que historicamente Ihe sobrou para vender: seu trabalho, tornado 
força de trabalho - aos ritmos de valorização e desvalorização do imóvel frente à produção urbana do espaço. Estes ritmos têm sido estreitamente conectados aos níveis mundiais de valorização financeira. É este o conteúdo maior que pretendemos abordar por meio da abertura de capitais nas incorporadoras, como um acesso possível ao debate da produção de uma escala necessária, da impossibilidade de absorver este ritmo compulsório no modo de vida urbano e da possível contradição apontada nestes termos.

Esta pesquisa tateia o caminho da ampliação do crédito e da dívida no modo de vida urbano. A ampliação do crédito conta com um agenciamento e organização do tempo futuro dos tomadores de empréstimos, ou melhor, conta com o comprometimento do trabalho futuro dos trabalhadores para a sua realização. Sabemos que a administração da inadimplência pode se transformar na elevação dos preços do crédito, desde o início da dívida, e também na passagem destas dívidas aos níveis superiores do sistema financeiro. A crise do trabalho apresenta o endividamento como inerente ao cotidiano do trabalhador, e a produção do espaço urbano está imbricada neste processo. Além disso, o crédito e a dívida são vistos aqui como relações sociais. A crise dos subprime americanos em 2008 provocou a lembrança deste conteúdo inserido nas relações financeiras, mas os conteúdos da produção do urbano estão por desvendar. Temos alguns complicadores, entretanto. O primeiro diz respeito ao fato de que as dívidas são vividas, muitas vezes, socialmente, de forma dramática. Não existe um caminho fácil para conversar sobre elas, muito menos para entrevistar pessoas endividadas. O segundo diz respeito ao fato dos processos atuais de endividamento serem generalizados, e, portanto, provocarem um estudo que considere as quantidades e a correta abordagem destas quantidades.

\section{O papel dos leilões na máquina produtiva urbana}

A pesquisa sobre os leilões está intimamente ligada ao estudo da produção da escala urbana. A partir da observação do aumento do número de lançamentos residenciais dos últimos dois anos, e da ritmação destes lançamentos em escala industrial para remuneração financeira mundial, chegamos à análise dos leilões como um momento necessário ao sistema produtivo urbano. Os entraves à produção do espaço em escala, no seu momento de realização da mercadoria, quando ela é comercializada, foram "resolvidos" pelo crédito. No caso de inadimplência, a partir de um suporte jurídico, já apresentado aqui no enfoque sobre a lei que traz a instituição da Alienação Fiduciária, novas articulações vão sendo apresentadas para a pronta retomada da mercadoria. Aí estão os leilões.

A partir de um acompanhamento sistemático nos anúncios dos leilões de instituições bancárias e de Leiloeiros, reunimos algumas observações:

- De forma indistinta, os leilões imóveis obedecem à solução de diversas situações de endividamento. Devemos entretanto ter em mente as principais razões de um leilão: podem ser resultado de dívida gerada pela cobrança das taxas de condomínio, ou de imóveis que entraram como garantia de compras de outras mercadorias, e por último, leilões gerados a partir dos contratos inadimplentes de alienação fiduciária do SFI, foco das nossas pesquisas. Esta última forma tem se tornado cada vez mais presente, especialmente a partir do momento em que a alienação fiduciária do imóvel passou a ser parte da prática de lastro dos financiamentos imobiliários e os leilões, com muito mais agilidade, passaram a responder ao processo de retomada do imóvel.

- os leilões participam de diversas formas na produção do espaço urbano, com imóveis arrematados a partir de compras individuais ou como prática de um negócio corporativo, pois algumas empresas escolhem o leilão como meio de comercialização dos seus lançamentos. Em Portugal, por exemplo, os leilões já 
participam francamente como um momento em que empresas se utilizam destes imóveis para reformá-los e revendê-los.

- As tipologias observadas nas listagens de leilões têm apresentado preponderância de imóveis destinados às baixas rendas, com a identificação, por exemplo, de imóveis em conjuntos habitacionais populares. Estas observações iniciais já nos trazem o possível impacto da dívida do imóvel urbano nas famílias de baixa renda.

- Devemos considerar dois tipos diferentes de leilões, extrajudiciais e judiciais. Existem muitos processos para revogação dos leilões extrajudiciais, fato a ser checado junto às associações de mutuários. São momentos distintos dos leilões, provocando bastante conflito entre quem perde o imóvel e quem o compra. Para um leilão ser considerado judicial também é necessário que todas as etapas do processo tenham ocorrido, dentre elas o aviso ao endividado.

- Grande parte dos imóveis leiloados está ocupado, e como deixa claro todo anúncio de leilões, a desocupação do imóvel, seus custos e negociação ficam por conta de quem arremata o bem. Devemos considerar aqui o fato de que o leilão atua sobre a propriedade, abstrata, sendo a posse resolvida de forma independente ao leilão. A compreensão sobre a atual regulamentação e agilidade no processo de leilões é de que estas são práticas que visam maior rapidez de circulação do produto "parado".

Precisamos, antes de tudo, absorver as recentes análises sobre os níveis de abstração aos quais a propriedade deve chegar para dar conta dela - a propriedade - ser elemento vivo e atuante nos sistemas de crédito $^{5}$, e da máquina produtiva urbana, de uma forma geral. O uso do imóvel é apenas um dos momentos da realização da propriedade. Assim, temos diversas etapas neste processo.
O imóvel representa, para quem o compra, a sua inserção possível no urbano, parte integrante da sua reprodução como trabalhador, como uma possível participação em relações sociais derivadas da moradia, e do morar na cidade. A estas escalas do morar, morar no urbano, num urbano desenhado a partir da jornada de trabalho, aportam-se as escalas mundiais de reprodução do capital financeiro, apresentando o ritmo de endividamento oriundo do uso do imóvel como o ritmo de trabalho a ser suportado pelo comprador.

No rompimento desta relação, novos conteúdos aderem à noção de propriedade presente no início da relação de crédito, pois notamos que a troca de moradores do imóvel é apenas um resíduo para a circulação do bem, uma vez que o leilão não diz respeito às ações de despejo.

\section{Considerações finais}

Nesta pesquisa identificamos que, para que o financiamento do imóvel se tornasse um propulsor importante nos níveis de produtividade da economia urbana, esta relação de crédito precisou ser expurgada do incômodo que a posse pudesse apresentar à propriedade. Assim, temos a forma como o leilão apresenta a capacidade de transferir a propriedade em seus termos abstratos, sem resolver sua condição concreta. Os conflitos sobre a posse são o resíduo do negócio, transferido ao comprador do imóvel que foi leiloado.

O valor do imóvel leiloado se torna o valor da dívida do imóvel. O preço inicial do imóvel que, aparentemente, "pagava" os atributos da sua situação geográfica, passa a ser o "preço" do endividamento. Assim, os valores presentes nos leilões não estão vinculados ao valor do imóvel propriamente dito, mas à dívida que o envolve. O valor do imóvel precisou mostrar sua verdadeira face: a despeito de toda a elaboração das teorias do preço da terra a partir apenas de sua localização, quando o crédito vira dívida, o leilão deve pagar não o preço do imóvel, mas o valor 
da dívida, ou seja, a valor projetado na programação e na assignação sobre o trabalho futuro.

Assim, para elucidarmos melhor os termos da máquina produtiva urbana se tornou necessário nesta pesquisa percorrer o caminho da produção da escala, por meio da formação dos land banks e da abrangência desta escala no urbano, para a necessária remuneração do capital financeiro. A produção e não a comercialização dos imóveis produzidos é o foco da indústria urbana, em um primeiro momento. Os imóveis produzidos, por sua vez, absorverão em seus preços a condição do mercado de capital financeiro mundial. Assim, valorizações fictícias do dinheiro podem ser incorporadas ao preço da terra e consequentemente do imóvel. Tratamos então de abordar a valorização do capital fictício, sob um prisma, e o aumento dos preços dos imóveis mediado pelo crédito, sob outro, à luz da renda da terra. O conteúdo do crédito é o trabalho futuro. A sua forma é a dívida, o endividamento e o mais crédito.

De forma generalizante, podemos compreender o nosso urbano atual na sua forma de reproduzir a propriedade abstrata em larga escala, produzir e reproduzir. A escala urbana metropolitana se apresenta ao urbano independente de suas dimensões geométricas. A escala urbana é uma escala social. As cidades de portes diversos vivem a condição abstrata e metropolitana da propriedade. Resta-nos trilhar o caminho das contradições, nos seus níveis.

\section{Notas}

1 Muitos fazem parte deste grupo, cada um a sua maneira. Para este momento, em particular, agradeço as infinitas colaborações de Ricardo Baitz, com sua profunda pesquisa nos analistas institucionais, e na generosidade de dividir com todos o que vem trazendo dali. Alexandre Rocha, Bruno Souza e Márcio Rufino oportunamente aceitaram sentar conosco no último Encontro Nacional de Geógrafos, ocorrido em São Paulo, e debateram as suas implicações nas pesquisas. Seus conhecimentos se tornaram parte da pesquisa de doutorado e portanto deste artigo.

2 Esta percepção da economista provavelmente seria revista se fossem levadas em conta inúmeras contratações e subcontratações relacionadas às obras.

${ }^{3}$ Listadas em TAVARES, R. (2008). Abyara e JHSF são consideradas pela autora como administradoras de bens ou corretoras imobiliárias, por isso não entram na lista acima, mas importam nesta pesquisa, em parte pelo material disponível e em parte, no caso da Abyara, pela sua expansão pelo país, e pela crise já apresentada e documentada.

4 "Owing or renting a home is probably the most important means of consumption, and certainly the most important expenditure in most people's lives. But homeownership is surrounded by a contradictory aura of both autonomy and dependence. On the one hand, owing the roof over the one's head, and a little plot of land around it, means liberation from the landlord or landlady and from boarding with relatives. On the other hand, eviction is just as likely at the hands of the bank or mortgage-holder, whose payment at regular intervals compels job stability, saving, and most important, staying in the place. Homeownership also indicates a relationship between investment and consumption. Over the past forty years, buying a home has become a ticket in the great sweepstakes of rising land values, as well as a traditional means of securing shelter. Yet owning a home may be a costly asset, the authors of a historical study of homeownership in the Boston area tell us. The social mobility it implies may in the long run bring only "the accumulation of devaluing assets". In the short run, moreover, because of the costs of buying and maintaining a home, a person's place in the housing market shapes his or her entry into the labor market." (ZUKIN, Sharon. Landscapes of power, p.11).

5 Este aporte teórico e prático devemos a Ricardo Baitz, na sua pesquisa de mestrado, e em especial nos mais recentes artigos. 


\section{Referências Bibliográficas}

BAITZ, Ricardo. O metrô chega ao centro da periferia: o estudo do concurso público nacional para reconversão urbana do Largo da Batata e da operação urbana Faria Lima em sua nova fase. Dissertação de mestrado - Programa de Pósgraduação em Geografia Humana, Departamento de Geografia. FFLCH - USP, 2004. 2V.

BOTELHO, Adriano. O urbano em fragmentos, a produção do espaço e da moradia pelas práticas do setor imobiliário. São Paulo: Annablume, Fapesp, 2007. 315 p.

CHESNAIS, F. (coord.). A Mundialização Financeira, Gêneses, custos e riscos, São Paulo: Ed. Xamã, 1998. 334 p.

DAMIANI, Amélia Luisa. (coord.) O futuro do trabalho: elementos para a discussão das taxas de mais-valia e de lucro. AGB - SP: 2006.

DEBORD, Guy. A sociedade do espetáculo: comentários sobre a sociedade do espetáculo. $1^{\text {a }}$ Ed. Rio de Janeiro: Ed. Contraponto, 1997. 237 p.

FIX, Mariana. São Paulo, Cidade Global. Fundamentos financeiros de uma miragem. São Paulo: Boitempo Editorial, 2007.

GONÇALVES, Carlos Walter Porto. Geografando Nos varadouros do mundo. Da territorialidade seringueira ou do seringal à reserva extrativista. Tese de Doutorado. Programa de Pós Gradução da universidade Federal do Rio de Janeiro, 551p, 1998.

HARVEY, David. Los límites del capitalismo y la teoría marxista. México: Fondo de Cultura Econômica. 1990. 457 p.
HARVEY, David. Espaços de Esperança. São Paulo: Edições Loyola, 2004.

JAPPE, A. Guy Debord. Petrópolis : Editora Vozes, 1999. $270 \mathrm{p}$.

LEFEBVRE, H. Éléments de Rythmanalyse, Introduction à la conaissance des rythmes. Editions Syllepse, 1992, 116p.

. La production de l'espace. Paris: Éditions Antrophos, 1974, 485 p.

. Introduccion a la Psicosociologia de la vida cotidiana. In: De lo rural a lo Urbano, antologia preparada por Mário Gavíria, ediciones Península, $215 \mathrm{p}$.

SILVA, Flávia Elaine da. Favela: que negócio é este? Dissertação de mestrado - Programa de Pós-graduação em Geografia Humana, Departamento de Geografia. FFLCH - USP, 2006.

SMITH, Neil. Contornos de uma política espacializada: veículos dos sem-teto e produção de escala geográfica, pp.132-159, in ARANTES A., Antonio (org.), "O Espaço da Diferença, Editora Papirus, 2000.

TAVARES, Rosana. A estrutura de financiamento das empresas brasileiras abertas do setor de construção civil incorporadas de empreendimentos imobiliários: um estudo comparativo, São Paulo, 2008, 160 p. Tese de Doutorado, FEA, USP.

ZUKIN, Sharon. Landscapes of power, from Detroit to Disney World. University of California Press. Los Angeles: 1993.

Trabalho enviado em outubro de 2009 Trabalho aceito em dezembro de 2009 